\title{
Universal product design involving elderly users: a participatory design model
}

\author{
Oya Demirbilek ${ }^{\mathrm{a}}$, Halime Demirkan ${ }^{\mathrm{b}, *}$ \\ ${ }^{a}$ Industrial Design, Faculty of the Built Environment, University of New South Wales, Sydney NSW 2052, Australia \\ ${ }^{\mathrm{b}}$ Department of Interior Architecture and Environmental Design, Faculty of Art, Design and Architecture, Bilkent University, \\ Bilkent 06800, Ankara, Turkey
}

Received 13 February 2001; received in revised form 3 December 2003; accepted 1 March 2004

\begin{abstract}
Recent studies have shown that people prefer to age in their familiar environments, thus guiding designers to provide a safe and functionally appropriate environment for ageing people, regardless of their physical conditions or limitations. Therefore, a participatory design model is proposed where human beings can improve their quality of life by promoting independence, as well as safety, useability and attractiveness of the residence. Brainstorming, scenario building, unstructured interviews, sketching and videotaping are used as techniques in the participatory design sessions. Quality deployment matrices are employed to find the relationships between the elderly user's requirements and design specifications. A case study was devised to apply and test the conceptual model phase of the proposed model.
\end{abstract}

(C) 2004 Elsevier Ltd. All rights reserved.

Keywords: Elderly user; Participatory design; Universal design

\section{Introduction}

Reviewing the literature related to design for the elderly with respect to the relationship between the person and environment shows that the subject is studied from various points of view. The designers are mostly interested in the physical attributes of housing, although researches have shown that psychological well being is one of the most intrinsic aspects of successful ageing (Carp, 1976; Lawton and Nahemow, 1973; Schwirian and Schwirian, 1993). Besides having the required physical characteristics, the physical environment itself should be used to form friendship and encourage socialisation and relationships. The design professional faces a tremendous task and challenges to keep abreast of technological advances and research pertaining to many facets of human beings and the built environment (Benktzon, 1993; Dagostino, 1996; Demirkan, 1996; Pinto et al., 2000; Sagdic and Demirkan, 2000).

\footnotetext{
*Corresponding author. Tel.: +90-312-290-1465; fax: +90-312-2664136.

E-mail address: demirkan@bilkent.edu.tr (H. Demirkan).
}

A house that is inadequate for the needs of the people living in it, never becomes a home. A wide spectrum of professions is concerned with life-span design (universal design) for an ageing population, design, engineering, gerontology, ergonomics and architecture. All try to support ageing in place so that independence, freedom of choice and life style are promoted. Designs considering the data related to both physical and psychosocial characteristics of people can improve the quality of life by promoting independence, as well as safety, useability and attractiveness of the residence (Demirbilek and Demirkan, 1998).

The elderly dealing with changed capacity, reduced ability and increased needs require the same accommodations and compensations in late life that they found in earlier years. Homes must provide solutions that address these distinctions in capacity, ability and need for daily living. Universal design is a concept that extends to a broad diversity of users who have to interact with the built environment (Sandhu, 2001; Scott et al., 2001; Steinfeld and Danfort, 1993; Story et al., 1998).

Sanoff (1990) claimed that "All designers who are concerned with improving the quality of their efforts and the quality of everyday life should consider 
participation through user involvement" (p.1). In fact, design is a project-oriented process and people execute design activities including problem solving documentation and communication among the parties. In order to achieve design goals effectively, the participation of individuals for sharing information, responsibilities and resources has to be organised (Ciccantelli and Magidson, 1993; Reich et al., 1996; Sanoff, 1990; 2000; Wulz, 1990). Therefore, this paper proposes the Useability, Safety, Attractiveness Participatory (USAP) Model based on a quality function deployment design system. Also, a case study is conducted for designing door and door accessories with participatory design sessions to test the conceptual design phase of the proposed model.

\section{Useability, Safety, Attractiveness Participatory (USAP) design model}

A participatory design model is proposed in order to design and develop safe and functionally appropriate products that will promote and maintain independent living of the elderly. There are five phases of the design model in order to transform a concept into a design description so that the artefact is capable of producing the determined functions. The phases of the USAP design model are depicted in Fig. 1.

\subsection{Concept development phase}

In the first phase of the design model, where the designer and the elderly participants are involved, participatory design sessions are organised with small groups of elderly people. The techniques that are applicable in participatory design sessions are scenario building (Fulton and Marsh, 2000), brainstorming, idea writing and sketching, unstructured interviews and asking pre-set questions (Wulz, 1990). At this phase, the participants produce ideas and define their exact needs and preferences pertaining to the artefacts. Due to the difficulties in extracting information from elderly people (Allan et al., 1996), the participatory design sessions are a combination of brainstorming, scenario building, and unstructured interviews, with written and oral parts, sketches, or gestures. The designer acts as an impartial moderator and the form of participation in this phase is an active dialogue (Wulz, 1990) in which the designer does not make any proposals for the design in the beginning but acts as a facilitator. The elderly users are the ones who make proposals during the design process. The participatory design sessions are recorded on videotapes to recall all details (especially body language and simultaneous talks) and to create a memory that can be stored and used again for similar studies (Demirbilek and Demirkan, 2000).

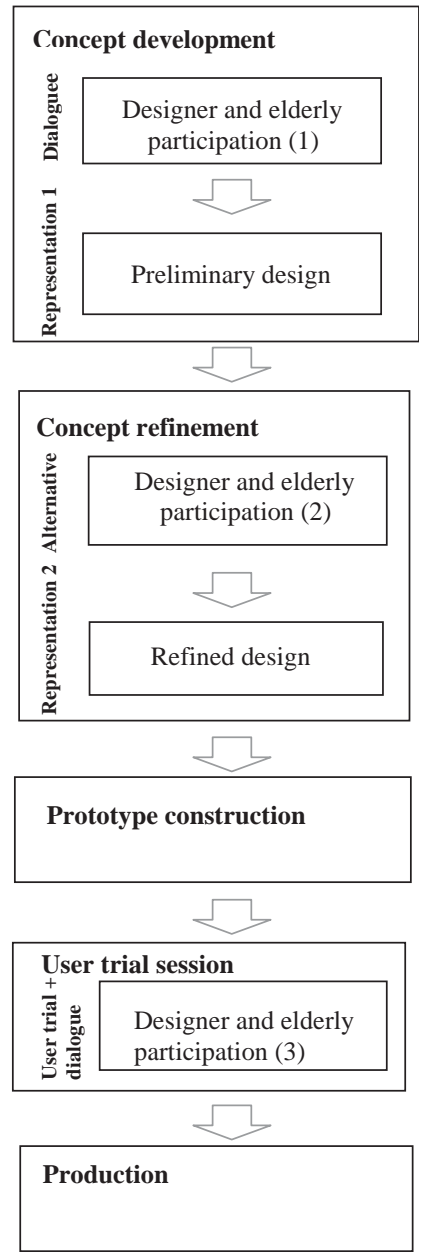

Fig. 1. The phases of the USAP design model.

In the second stage of the concept development phase of the design model, the designer analyses the problem, prepares a feasibility study and tries to find an optimal solution to the problem by satisfying the requirements and proposals of the elderly users. The designer's knowledge base is composed of three different sources: "relevant media, relevant domain, and relevant community" (Demirkan, 1998, p. 233). Relevant media involve knowledge from books, journals and videotapes. Relevant domain consists of observed cases from another source and the experience of the designer or other experts. Relevant community is all users of the artefact, experts and other relevant parties.

All the data collected during the first stage, including the answers to the pre-set questions, proposals, requirements and ideas, are classified in the USAP design model, using a quality function deployment design system (Sivaloganathan, et al., 1995) to develop the USAP deployment matrices (See Fig. 2). In these matrices, relationships between elderly users' requirements, and wishes, ideas and the technical design specifications are determined. This stage is not an act of participation, since the designer is the only one to be 


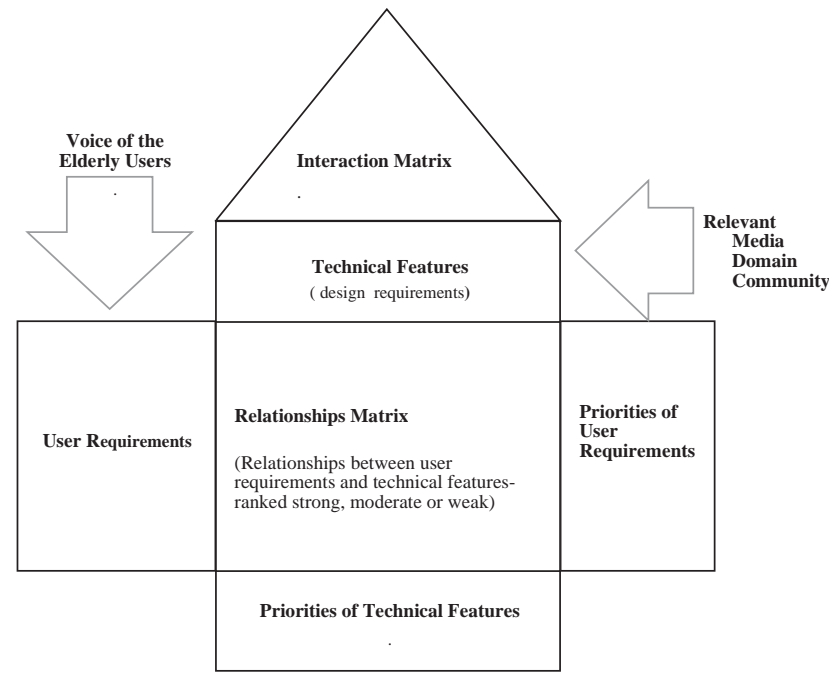

Fig. 2. The USAP deployment matrix.

involved in it. It is a representation, where the designer represents the elderly users by interpreting their real desires and proposals and matches them with her/his own previous knowledge. This is a less personal and less subjective representation, because the designer is better informed on the real requirements and needs of the elderly users. $\mathrm{He} / \mathrm{she}$ can combine the information obtained from the first stage with his/her knowledge and findings in the field. According to Eason (1995), this kind of combination is a mixture of two approaches, namely design by users and design for users. Eason (1995) also claimed that mixing the two approaches gives better results with higher success rates.

\subsection{Concept refinement phase}

In the second phase of the model, the conceptual design solutions are introduced to the elderly users in a second participatory session. During this session, the elderly users are asked to criticise the drawings, modify and make comments on the design alternatives sketched by the designer. At this phase, the participation form is an alternative one (Wulz, 1990). The elderly users could see and perceive the representations of the ideas and the propositions that they had made in the first phase and had been filtered through the knowledge and the interpretation of the designer, using USAP deployment matrices. The sketches are criticised, corrected and modified by the elderly users who act as jury members. The designer is the presenter and the facilitator. This phase tries to avoid misunderstandings and inaccurate interpretations of the designer, and reinforces the design descriptions through the approvals of the elderly participants (Demirbilek et al. 2000).

The second stage of the concept refinement phase consists of further developments and refinements of the design solutions. It involves the technical and detailed drawings of the products. In this stage, being similar to the preliminary design, the designer uses his/ her knowledge base and makes new representations to the elderly users by interpreting their preferences and corrections found during the second participatory session. In addition, the designer makes consultation with ergonomists and engineers. This is a step for refinement of the data recorded in the second participatory design sessions (Demirbilek and Demirkan, 2000).

\subsection{Prototype construction}

The third phase is the prototype construction and planning, with the production of detailed technical drawings, at the end of which prototypes are to be produced. In this phase, the designer works as a team with ergonomists and engineers.

\subsection{User trial}

The fourth phase is the trial of the prototype of the designed artefact by the elderly participants. In this phase, the participation takes a user trial (Wulz, 1990) form combined with a dialogue form of participation. The team comprises a designer, and an ergonomist who observe the elderly users trying the prototype while discussing the design. The comments and new ideas of elderly end-users are again recorded to recall all the details and to create a knowledge domain for similar projects in the future.

\subsection{Production}

The production phase is the last phase of the application development process. The artefact is manufactured and provided to the consumers.

\section{The case study}

In order to test the USAP design model, a study was conducted with a focused group of elderly people. Two different participatory design sessions (each consisting of three groups) were held during the concept model phase. The end-users were asked to participate in the design process of doors and door handles for the house that they want to age in, considering all their possible requirements, needs, particular wishes and ideas. The first author of this paper was the designer in this case study. The participatory design sessions are conducted within the scope of her doctoral dissertation (Demirbilek, 1999) at Bilkent University. 


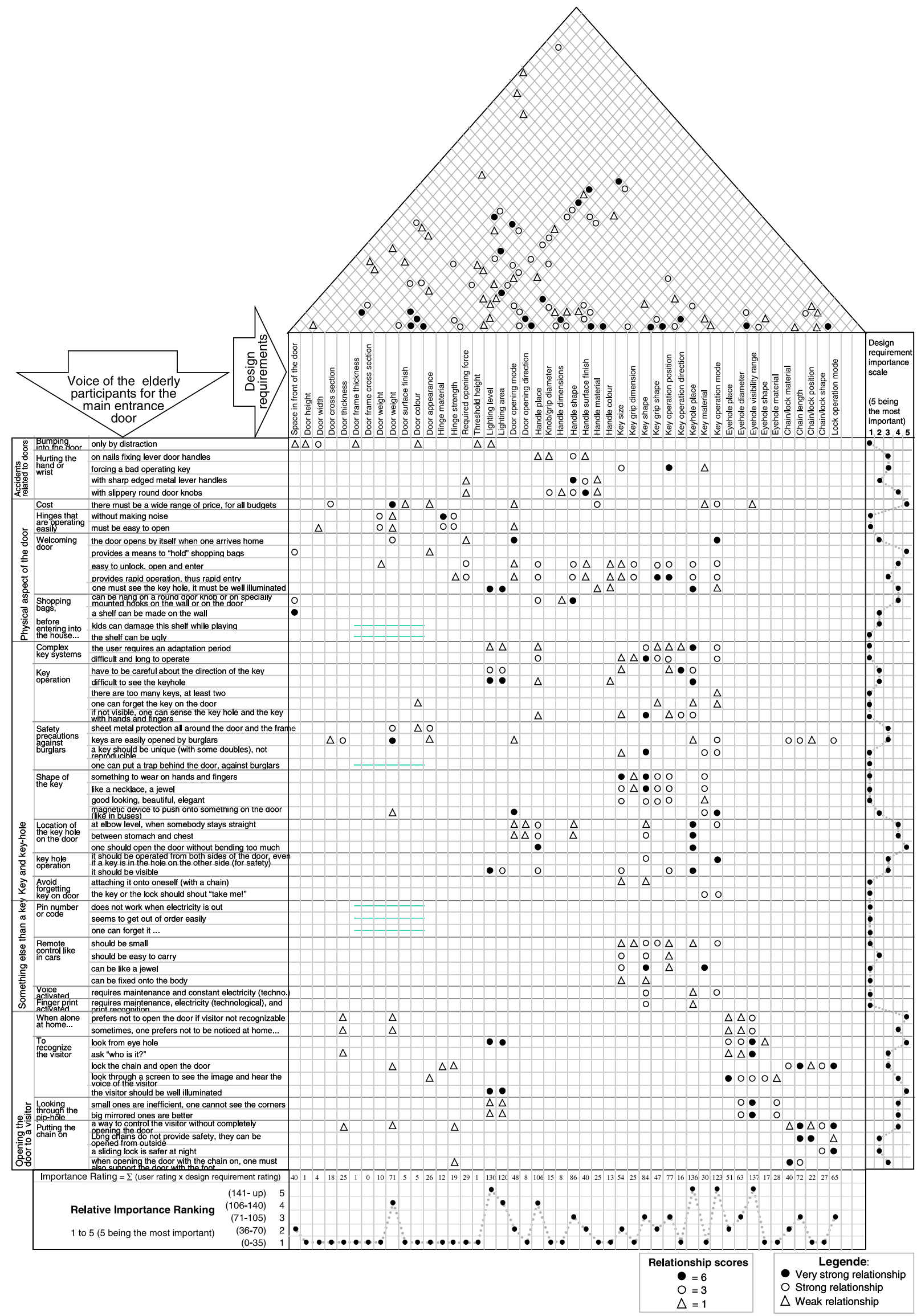

Fig. 3. The USAP deployment matrix for entrance doors. 


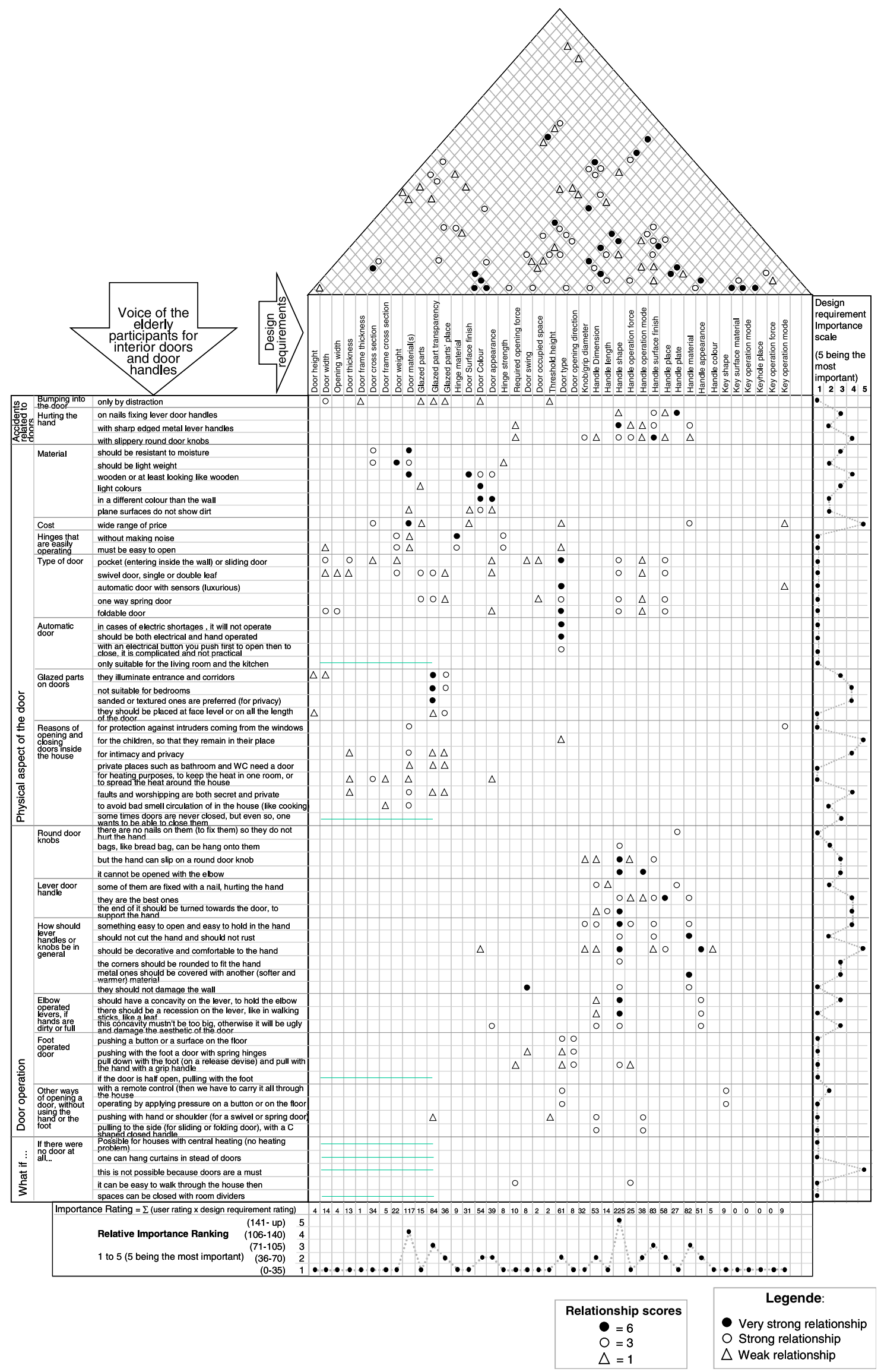

Fig. 4. The USAP deployment matrix for interior doors and door handles. 


\subsection{Participants}

The participatory design sessions were held with focus groups consisting of male and female end-users above the age 65, from the city of Ankara, Turkey. A sample of 13 potential elderly end-users forming three different groups took part in the research, each completing both participatory design sessions (Demirbilek, 1999). The sample of volunteers consisted of 10 females and 3 males with mean age 75 . A pilot session was conducted with 4 elderly participants (one male and three females between 68 and 75 years old) and the participatory design session was revised accordingly.

Jones (1992) claimed that small groups consisting of 6 people successfully produce up to 150 ideas in half an hour at their first attempt. Barrett and Kirk (2000) found an absence of guidelines on planning and running focus groups with special considerations for elderly participants; they aimed to use 6 people as minimum focus group size. Since this study involves a design process, the groups had participants 3, 4 and 6, respectively, with 1 male in each. Each session lasted between 40 and $50 \mathrm{~min}$.

Table 1

Classification of design requirements of the entrance door

\begin{tabular}{|c|c|c|}
\hline Most important & Moderately important & Less important \\
\hline $\begin{array}{l}\text { Eyehole visibility } \\
\text { range }\end{array}$ & Handle shape & $\begin{array}{l}\text { Space in front of the } \\
\text { door }\end{array}$ \\
\hline Keyhole place & Key shape & Door height \\
\hline Lighting level & $\begin{array}{l}\text { Key operation } \\
\text { position }\end{array}$ & Door width \\
\hline $\begin{array}{l}\text { Key operation } \\
\text { mode }\end{array}$ & Chain length & Door cross section \\
\hline Lighting area & Door material & Door thickness \\
\hline Handle place & $\begin{array}{l}\text { Lock operation mode } \\
\text { Eyehole diameter } \\
\text { Key size } \\
\text { Eyehole place } \\
\text { Key grip shape }\end{array}$ & $\begin{array}{l}\text { Door frame thickness } \\
\text { Door frame cross section } \\
\text { Door weight } \\
\text { Door surface finish } \\
\text { Door colour } \\
\text { Door appearance } \\
\text { Hinge material } \\
\text { Hinge strength } \\
\text { Required opening force } \\
\text { Threshold height } \\
\text { Door opening mode } \\
\text { Door opening direction } \\
\text { Knob/grip diameter } \\
\text { Handle dimensions } \\
\text { Handle surface finish } \\
\text { Handle material } \\
\text { Handle colour } \\
\text { Key grip dimension } \\
\text { Key operation direction } \\
\text { Key material } \\
\text { Eyehole shape } \\
\text { Eyehole material } \\
\text { Chain/lock material } \\
\text { Chain/lock position } \\
\text { Chain/lock shape }\end{array}$ \\
\hline
\end{tabular}

\subsection{Participatory design sessions}

In the USAP design model, two different participatory design sessions were held. In the first participatory design session the designer and the participants were seated around a table, having papers, pens and a blank page. The reason was to make them control the design process and consider themselves to be equal partners in the process. No perfect drawings were expected and the intention here was to see if they could use sketching as a tool to express their ideas. The outputs of these design sessions did not aim to end up with finished products or designs, but only to initiate the design process.

In this study, the designer used scenario building technique, unstructured interviews and asked eight preset groups of questions related to the design of doors and door handles (Demirbilek, 1999). These questions were grouped under the following headings:

- problems faced with main entrance door,

- problems with keys while opening or closing doors,

- door safety while opening and closing doors,

- reasons for closing doors in interiors,

- problems and recommendations on door handles and knobs,

- problems and recommendations related to the glazed parts on doors,

Table 2

Classification of design requirements of the interior doors and door handles

\begin{tabular}{|c|c|c|}
\hline Most important & Moderately important & Less important \\
\hline Handle shape & Door appearance & Door height \\
\hline Door material(s) & $\begin{array}{l}\text { Handle operation } \\
\text { mode }\end{array}$ & Door width \\
\hline $\begin{array}{l}\text { Glazed part } \\
\text { transparency }\end{array}$ & Glazed parts' place & Opening width \\
\hline $\begin{array}{l}\text { Handle surface } \\
\text { finish }\end{array}$ & Door cross section & Door thickness \\
\hline Handle material & Knob/grip diameter & Door frame thickness \\
\hline Door type & Door surface finish & $\begin{array}{l}\text { Door frame cross } \\
\text { section }\end{array}$ \\
\hline Handle place & & Door weight \\
\hline Door colour & & Glazed parts \\
\hline Handle dimension & & Hinge material \\
\hline \multirow[t]{15}{*}{ Handle appearance } & & Hinge strength \\
\hline & & Required opening force \\
\hline & & Door swing \\
\hline & & Door occupied space \\
\hline & & Threshold height \\
\hline & & Door opening direction \\
\hline & & Handle length \\
\hline & & Handle operation force \\
\hline & & Handle plate \\
\hline & & Handle colour \\
\hline & & Key shape \\
\hline & & Key surface material \\
\hline & & Key operation mode \\
\hline & & Keyhole place \\
\hline & & Key operation force \\
\hline
\end{tabular}




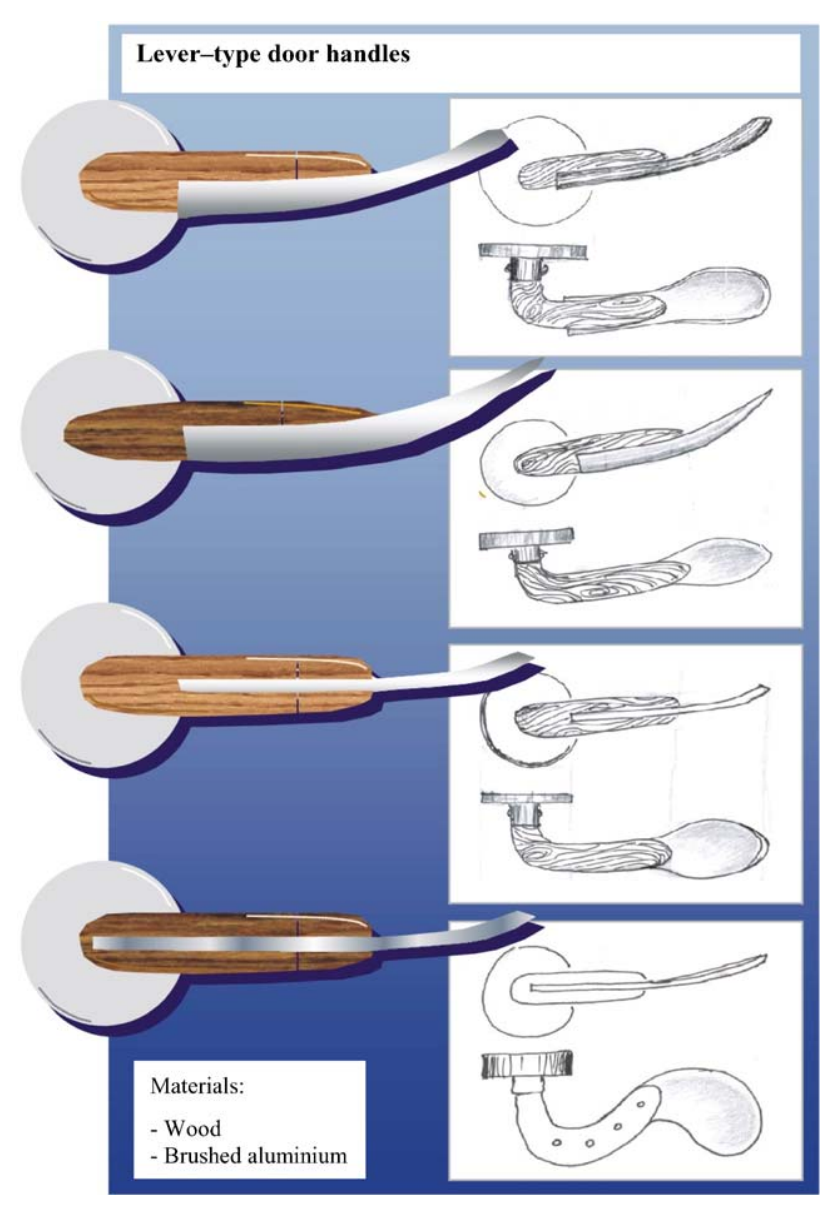

Fig. 5. Sketches of door handles.

- problems and recommendations related to the material choice,

- different door types.

In order to help the participants to express themselves more freely, without being limited by the questions, the designer introduced some scenarios. As the participants started to create various scenarios, the designer encouraged them to start brain storming in order to propose any kind of solutions to the problems that they can be faced with.

Some examples of the scenarios used during these sessions are as follows:

- You are coming back from shopping, hands full. Nobody is at home and you have to open the door. The keys are somewhere deep in your bag (or pocket). What do you do?

- You are in the kitchen preparing a meal, the door is closed, and your hands are all greasy and dirty. The telephone is ringing in the other room. How do you open the kitchen door?

- You are alone at home. Somebody rings at the door. You look from the eyehole but you cannot see the visitor well. What do you do?
The designer asked the participants to tell their ideas, whether positive, negative, or neutral during the scenarios. For any stated negative points by the participants, the designer asked them how it can be improved, and how the related parts can be designed. The designer while writing down the comments and ideas of the participants encouraged them to draw or write on the papers. Also, the information was recorded on video for later evaluation. The analysis of the videotapes allowed a full range of behavioural traits and the sequence of events to be observed (Demirbilek and Demirkan, 2000).

After the completion of the first set of participatory design sessions, the outputs (responses to the questions, drawings, and additional comments) had been grouped under several topics such as door characteristics, door operation and accidents related to doors. The USAP deployment (see Figs. 3 and 4) matrices were formed to find the existing relationships between the elderly requirements and the technical design considerations for entrance and interior doors.

In the second participatory design session, the designer presented the drawings that were formed as the outputs of the first session. The presentations were in the form of hand and computer sketches, not too perfectly drawn to avoid the feeling that every thing has already been decided, and nothing was left for them. Each participant received the copies of the drawings on which he/she can criticise and redraw. The designer encouraged the subjects to express their ideas and make corrections on the sketches. All comments and drawings revised by the participants were collected at the end of the session. Discussions were recorded by note taking and on video.

\section{Results}

\subsection{Results related to the first participatory design sessions}

After the analysis of data, the important issues determined by the elderly users were introduced into the matrices to categorise the relationships between the elderly users' requirements, design limitations, and technical requirements. The matrices were prepared based on the knowledge accumulated both from the participatory design sessions and the relevant media, domain and community. Both the elderly users' requirements and the design specifications were rated on a 5-point numerical scale (see Figs. 3 and 4). For the elderly users' requirements, the importance was rated according to the number of participants having (or approving) the same opinion. For the design specifications related to the design of a door, the importance was rated according to the professional knowledge of the designer. 
The results obtained from quality deployment matrices were grouped under three categories as the most, moderately or less important for the main entrance door and the interior doors and door handles (Tables 1 and 2, respectively).

Based on the knowledge extracted from the matrices, three preliminary design sketches were generated in the second stage of the conceptual development phase of the participatory design model. Among them, an elbow operated door handle (see Fig. 5) and a door screen (see Fig. 6) that will allow elderly users to see a visitor without having to go near the door were proposed. Another proposal was a device at the main entrance door, being a shelf for shopping bags or a seating unit while searching for keys in the bag (see Fig. 7).

\subsection{Results related to the second participatory design sessions}

During the second participatory design sessions, the elderly participants seemed more comfortable, since they were familiar with the process. They listened carefully to the explanations related to the representations of the design concepts and made their comments. Some corrections were made on the given drawings.

Among the three designs presented to the elderly, the lever handle to be operated with an elbow was corrected a great deal. The designed lever handle can be operated with an elbow as well as hand. It was designed with a wood or plastic material covering in order to provide a softer contact with the hand (see Fig. 5). The concave protruding metal part was designed for the elbow operation. The elderly participants stated that the metal part, being thin, acts as a sharp edge to injure the users. Two of them proposed to cover it completely with wood, while keeping the metal part in the middle for strength. They also said that the varnish of the wood must not be too shiny to avoid the elbow slipping (Demirbilek, 1999).

The folding shelf/stool (see Fig. 7) fixed to the wall at the main entrance door was also corrected. The proposals were made about the fixing details. The door screen was accepted and was appreciated by all of the participants. No corrections were made on the drawings.

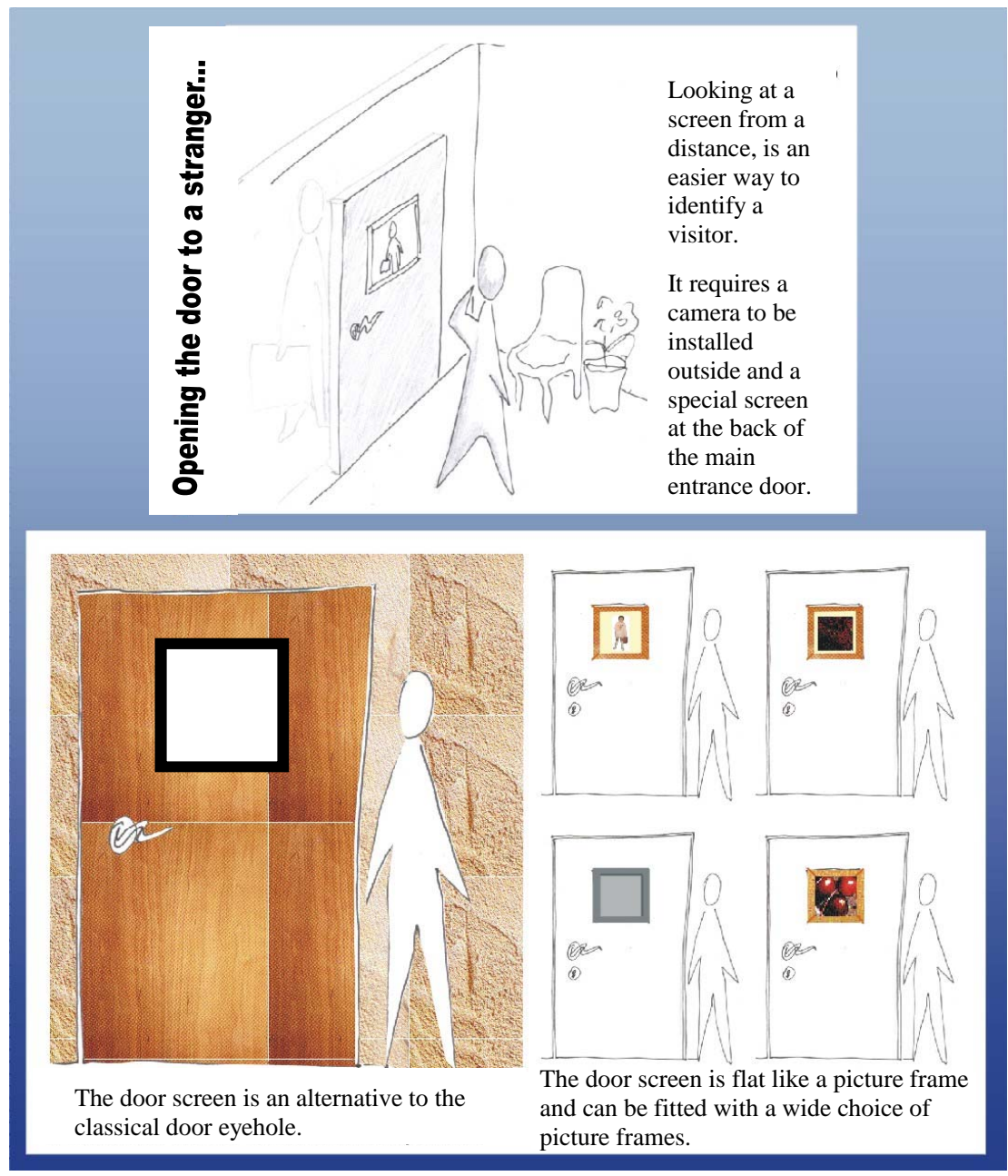

Fig. 6. Sketches of door screens. 


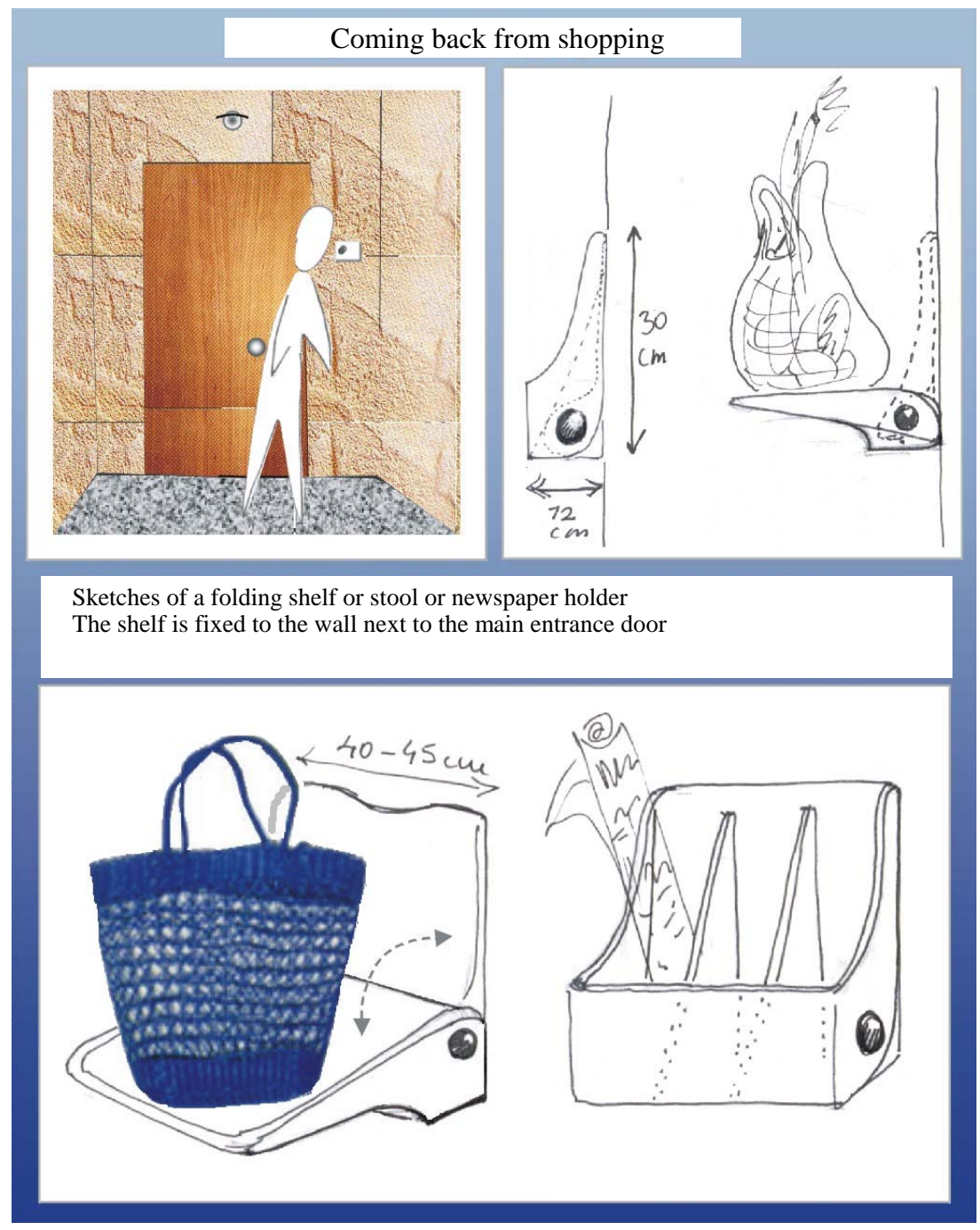

Fig. 7. Sketches of multi-functional shelves.

\section{Conclusions}

A participatory design model was proposed in order to design and develop safe and functionally appropriate housing that will promote and maintain independent living of elderly people. There is a growing recognition that the physical environment can enhance or impede the independence and mobility of the elderly. Sanoff (2000) stated that "the elderly, a rich resource of knowledge and experience, have often been excluded from the design process" ... although they are not a homogenous group they are... "unique individuals with a common goal-living life with dignity" (p. 208). The sketches proved that involving the elderly in the design decision making process enhances the design solutions, since the experience of the users was reflected in the final design descriptions. Also, the participatory design sessions increased elderly people's awareness of the consequences of the decisions that were taken, as well and they gained satisfaction by having influenced the decisions.
The quality function deployment system represents a very suitable way to incorporate the needs and requirements of the elderly user into the design process. In this study, the deployment matrices helped to reach the real needs and requirements of the elderly users accurately to provide their original contribution to the design process. Elderly people have shown a very good performance during the participatory design sessions and USAP deployment matrices have proven to be potential source for designers that must be explored more deeply. This study only involved the conceptual design phase of the design process and it should be tool for further phases of the design process.

\section{References}

Allan, J., Khong, C.W., Gilhaum, B., Hall, S., Kerwood, J., Macdonald, A., McNally, N., Nelson, D., Page, S., Stewart, S., Stovell, D., 1996. The Challenge of Age. Glasgow School of Art, The Foulis Press, Glasgow. 
Barrett, J., Kirk, S., 2000. Running focus groups with elderly and disabled participants. Appl. Ergon. 31 (6), 621-629.

Benktzon, M., 1993. Designing for our future selves: the Swedish experience. Appl. Ergon. 24 (1), 19-27.

Carp, F.M., 1976. Housing and living environments of older people. In: Bistockm, R.H., Shanas, E. (Eds.), Handbook of Ageing and the Social Sciences. Van Nostrand, New York, pp. 244-271.

Ciccantelli, S., Magidson, J., 1993. From experience: consumer idealized design: involving consumers in the product development process. J. Product Innovation Manage. 10 (4), 341-347.

Dagostino, F.R., 1996. Universal design: barrier free living. CAAR Real Estate Weekly. http://www.caar.com/REW/Edit\%20Archives/Universal. Design. Retrieved on June, 7, 1997.

Demirbilek, O., 1999. Involving the elderly in the design process: a participatory design model for usability, safety and attractiveness, Ph.D. Thesis, Bilkent University, Ankara.

Demirbilek, O., Demirkan, H., 1998. Involving the elderly in the design process. Archit. Sci. Rev. 41 (4), 157-163.

Demirbilek, O., Demirkan, H., 2000. Collaborating with elderly endusers in design process. In: Scrivener, S.A.R., Ball, L.J., Woodcock, A. (Eds.), Collaborative Design. Springer, London, pp. 205-212.

Demirbilek, O., Demirkan, H., Alyanak, S., 2000. Designing an armchair and a door with elderly users, Designing for the 21st Century, An International Conference on Universal Design, June 14-18, http://www.adaptenv.org/21 century/proceedings5. asp\#parmchair. Retrieved on June 1, 2000, pp. 1-3.

Demirkan, H., 1996. Adaptable house design. In: Proceedings of XXIVth IAHS World Housing Congress. Ankara, Turkey, 27-31 May, (1), pp.19-29.

Demirkan, H., 1998. Integration of reasoning systems in architectural modeling activities. Automat. Constr. 7 (1-2), 229-236.

Eason, K.D., 1995. User centered design: For users or by users? Ergonomics 38 (8), 1667-1673.

Fulton, J.S., Marsh, M., 2000. Scenario building as an ergonomics method in consumer product design. Appl. Ergon. 31 (2), 151-157.

Jones, C.J., 1992. Design Methods: Seeds of Human Future, 2nd Edition. Van Nostrand Reinhold, New York.

Lawton, M.P., Nahemow, L., 1973. Ecology and the ageing process: psychology of adult development and ageing. In: Eisdorfer, C., Lawton, M.P. (Eds.), Psychology of Adult
Development and Ageing. American Psychology Association, Washington, pp. 619-674.

Pinto, R.M., De Medici, S., Sant, V.C., Bianchi, A., Zlotnicki, A., Napoli, C., 2000. Ergonomics, gerontechnology, and design for the home-environment. Appl. Ergon. 31 (3), 317-322.

Reich, Y., Konda, S.L., Monarch, I.A., Levy, S.N., Subrahamanian, E., 1996. Varieties and issues of participation. Design Stud. 17 (2), $165-180$.

Sandhu, J.S., 2001. An integrated approach to universal design: toward the inclusion of all ages, cultures and diversity. In: Preiser, W.F.E., Ostroff, E. (Eds.), Universal Design Handbook. McGrawHill, New York, pp. 3.3-3.14.

Sagdic, Y., Demirkan, H., 2000. A design decision support system model for the wet space renovation of elderly people's residences. Archit. Sci. Rev. 43 (3), 125-132.

Sanoff, H., 1990. Participatory Design: Theory and Techniques. Bookmasters, Raleigh, NC.

Sanoff, H., 2000. Community Participation Methods in Design and Planning. Wiley, New York.

Schwirian, K.P., Schwirian, P.M., 1993. Neighboring, residential satisfaction and psychological well-being in urban elders. J. Community Psychology 21, 285-297.

Scott, M.A.C., Nowlan, S., Gutman, G., 2001. Progressive housing design and home technologies in Canada. In: Preiser, W.F.E., Ostroff, E. (Eds.), Universal Design Handbook. McGraw-Hill, New York, pp. 36.1-36.15.

Sivaloganathan, S., Evbuomwan, N.F.O., Jebb, A., Wynn, H.Q., 1995. Design function deployment-a design system for the future. Design Stud. 4 (4), 447-470.

Steinfeld, E., Danfort, S., 1993. Automated doors: towards universal design. IDEA Publications, SUNNY/Buffalo: The Center for Inclusive Design and Environmental Access, http://www.adaptenv.org/ idea/publications/papers/autodoor_art.html, Retrieved on 11, 3, 1997.

Story, M.F., Mueller, J.L., Mace, R.L., 1998. The universal design file: designing for people of all ages and abilities. The Centre for Universal Design, NC.

Wulz, F., 1990. The concept of participation. In: Sanoff, H. (Ed.), Participatory Design: Theory and Techniques. Bookmasters, Raleigh, NC. 